\title{
Calorific Optimization Design of Waste Biomass Using Response Surface Method (RSM)
}

\author{
Jin Kyung Jo, Yong Gyun Jin, Eun Ji Jo, Wan Soo Hyeon, Seon Woong Min, and Woon Ho Yeo
}

\begin{abstract}
The optimization of Bio-SRF is conducted by mixing sewage sludge with waste sawdust and coffee grounds to improve high moisture content and low calorific value. grounds(1 5g).This study was aimed at put the sewage sludge(2 10g), waste sawdust(1 5g) and coffee grounds(1 5g) as variables using RSM (Three-dimensional analysis \& Central composite design).The result is [sewage sludge $(2.0 \mathrm{~g})$, waste sawdust $(1.0 \mathrm{~g})$, coffee grounds(5.0g)] and 0.9872 as $R$-square(adj). Forecast data is reported 4,574.26 kcal/kg above the condition.
\end{abstract}

Index Terms-Response surface method, waste biomass, bio-SRF, high calorific fuel.

\section{INTRODUCTION}

It is important to develop biofuel energy worldwide in order to reduce greenhouse gas. To be commercialized, calorific value of biofuel is needed to improve compared with that of fossil fuel. It is good to make most use of sustainable and economical waste biomass that fit into the situation in Republic of Korea.

The sewage sludge is used to a part of feedstock for biofuel under current law. However, it contains about $80 \%$ water structurally and causes a lot of trouble in terms of intractability.

A study on drying of sludge is under active discussion but domestic technology is in the initial phase. To prevent wasting drying power, there is a need to actively review for a mixture which has the high and low moisture contents of biomass [1].

So, this study used continuously generated sawdust and coffee grounds to upgrade calorific value.

The sawdust has components similar to lignocellulosic biomass. Also, it is eco-friendly because those play an important role in the glue [2].

The coffee grounds mean the residue left from extracted green coffee beans. It contains about $60-70 \%$ but this expect diverse fuel resourses as $2 \%$ ash and calorific value 5,855 $\mathrm{kcal} / \mathrm{kg}$ [3].

Industrial testing for producing ideal fuel is required the statistical approach because the time and cost [4].

This study uses the statistical tool "Response Surface Method (RSM)". RSM is a program to predict the optimum data using relationship among variables.

Manuscript received August 15, 2016; revised February 13, 2017. This work was supported in part by the Korea.

The authors are with Incheon National University, Development of Environmental Energy Engineering CO 22012, Korea (e-mail: 1905jo@naver.com, jyk071919@naver.com, whdmswl112@naver.com, lowellhyeon@naver.com,21428msw@naver.com, whyeo@inu.ac.kr).
RSM had conducted mostly manufacture of food and antioxidant activity [5], [6]. This paper adopted methodology to determine the fuel recipe similar to cooking recipe.

Thus, this research tests a property of matter as the basis. And then this study represents to decide optimal mixed ratio using RSM for high caloric fuel.

\section{EXPERIMENTAL METHOD}

\section{A. Raw Material}

It was selected as the samples; five species of the sewage sludge, four species of waste sawdust and one of the coffee grounds generated in the country. It was used the sewage sludge as raw sludge (moisture content: about $80 \%$ ) and waste sawdust after demolition of building materials.

Coffee grounds was the residue extracted green coffee beans from Brazil, Kenya AA, Colombia and Costa Rica. The sample is collected by conical quartering according to "Official Waste Test Method" [7]. It is shipped within twenty-four hours and used completely shredding for less than $1 \mathrm{~mm}$.

\section{B. Preparation Experiment}

This study carry out six kinds of experiment (Proximate , Calorie, Biomass contents and Aerobic Activate Respiration). All experiment conduct to repeat 3 times according to "Official Wastes Test Method" [8].

\section{1) Proximate analysis}

It conducts analysis of moisture, ash, volatile matterc matter and fixed carbon. Ash Samples were measured the moisture contents before and after drying. It was determined by combustion ash at $550 \pm 10^{\circ} \mathrm{C}$, volatile matter at $925 \pm 5^{\circ} \mathrm{C}$ during constant weight. Fixed carbon was obtained by calculation.

\section{2) Calorific value}

The calorific value of solid fuels is an important indicator for determining fuel quality. That presents SRF standards that must be met to achieve these objectives "enforcement rule on the promotion of saving and recycling of resourses" in Korea.

It utilizes the calorific value for priority of combination.

To measure its calorie, this use calorimeter (Parr6100, USA) It combusts about $1 \mathrm{~g}$ using 40psi oxidant and analyzes by measuring the temperature change of the distilled water.

\section{3) Ultimate analysis}

It analyzed C, H, N, S using Elemental Analyzer (FLASH 1112, Thermo Fisher Scientific), and calculated $\mathrm{O}$ by subtracting 
others. Air pollutant is influenced by elemental composition during combustion of bio solid fuel. Samples convert generated gas into $\mathrm{CO}_{2}, \mathrm{H}_{2} \mathrm{O}, \mathrm{N}_{2}, \mathrm{SO}_{2}$ via oxidation and reduction. And then oxygen was found by TCD (Thermal Conductivity Detector) after detaching a column. Also, these components can be decided conversion of HHV (High Heating Value) and LHV (Low Heating Value).

\section{4) Biomass contents}

There were two methods to test manual sorting and selective dissolution method (SDM). Measurement of biomass contents is based on "BS EN 15440". Manual sorting is visible bulky wastes more than $10 \mathrm{~mm}$. This study was used SDM because they do not fit in the waste biomass.

To test biomass contents, it is needed two $5 \mathrm{~g}$ samples. One gauges the ash content, the other is used to react $80 \%$ sulfuric acid $150 \mathrm{ml}(16 \pm 2$ hours left) and $35 \%$ hydrogen peroxide $30 \mathrm{ml}(4 \pm 1$ hours). And then those filter with purified water. They are calculated after measuring the weight.

- Aerobic Activate Respiration(AT4)

AT4 is evaluated by pressure changed by organism breathing in closed container. It makes the water holding capacity set $50 \%$ to $70 \%$ into the dried sample adding to pure water. After 12- 24hours fermentation, it absorbs carbon dioxide with $20 \% \mathrm{NaOH}$. And then observe the changed pressure of the subject during 4 days.

- Aerobic Activate Respiration(AT4)

AT4 is evaluated by pressure changed by organism breathing in closed container. It makes the water holding capacity set $50 \%$ to $70 \%$ into the dried sample adding to pure water. After 12- 24hours fermentation, it absorbs carbon dioxide with $20 \% \mathrm{NaOH}$. And then observe the changed pressure of the subject during 4 days.

\section{Experimental Design}

TABLE I: INDEPENDENT VARIABLES AND THEIR LEVELS FOR THE CENTRAL COMPOSITE DESIGN (CCD) EXPERIMENT

\begin{tabular}{|c|c|c|c|c|c|}
\hline \multirow{2}{*}{$\begin{array}{c}\text { Independent } \\
\text { variables }\end{array}$} & \multicolumn{5}{|c|}{ Limits and levels } \\
\hline & -2 & -1 & 0 & +1 & +2 \\
\hline Sewage Sludge & 2.0 & 4.0 & 6.0 & 8.0 & 10.0 \\
\hline Waste Sawdust & 1.0 & 2.0 & 3.0 & 4.0 & 5.0 \\
\hline $\begin{array}{c}\text { Coffee } \\
\text { Grounds }\end{array}$ & 1.0 & 2.0 & 3.0 & 4.0 & 5.0 \\
\hline
\end{tabular}

Each sample through a series of preliminary tests was brought up for variables that influence product quality. After you identify the process conditions and product components that influence product quality, you can direct improvement efforts to enhance a product's manufacturability, reliability, quality, and field performance.

A total of sixteen experiments including six factorial, eight axial and two center points carried out central composite design (CCD).

Depending on the experimental conditions, it made a fuel mixture material. The amount used of that put SS $(2 \mathrm{~g}, 4 \mathrm{~g}, 6 \mathrm{~g}$, $8 \mathrm{~g}, 10 \mathrm{~g})$, WS and CG(1g, 2g, 3g, 4g, 5g) as presented Table I.

\section{1) Regression model}

Each SS, WS, CG was set to the independent variables X1, $\mathrm{X} 2, \mathrm{X} 3$ respectively. Also, it is set to "Calorific Value" that the most important characteristics of the fuel as a dependent variable.

Analyze the correlation among variables by regression model. If $\mathrm{p}$-value is less than 0.05 , modeling has a lot significance.

\section{2) Resonse surface method (RSM)}

RSM is to derive a polynomial regression with least squares method to the design of experiments devised the Box and Wilson figured to predict the optimum conditions [9]. CCD (Central Composite Design) is used primarily for food production process research.

This paper is used Response Surface Method for estimating the optimum composition of the fuel with a minimum of experiment and Minitab software 17.0 version (Minitab Inc. USA) for the simulation of quality of forecasting on Bio-SRF.

Test method is as follows:

1) Determine the variables as influencing factors

2) Input parameter: factorial, axial a center point of the sample through extracting randomly.

3) Setting the range of variables and encoding

4) Analyze a regression model (ANOVA) and Lack of Fit

5) Illustrate a three-dimensional graph (the response surface method) and Predict the optimum data.

According to Eq. [10], Each input parameter was coded into five levels as $-2,-1,0,+1$ and +2 according to Eq. [10]

$$
\text { CodedValue }=Z i=\frac{X i-X o}{\Delta X}
$$

$$
\begin{aligned}
& Z i=\text { Coded Variables } \\
& X i=\text { Variables } \\
& X o=\text { Center point of the experiment range } \\
& \Delta X=\text { Stage Change }
\end{aligned}
$$

\section{RESULTS AND DISCUSSION}

\section{A. Material Characterization}

As presented Table II, it presents the results of sample characteristic analysis.

By proximate testing, it is confirmed that the moisture content of the SS and CG have $81.81 \%, 63.01 \%$ respectively.

This means are the high moisture biomass. Whereas WS is proved the low moisture biomass because of $6.3 \%$ moisture content. Calorific Value of SS is average $3,764.88 \mathrm{kcal} / \mathrm{kg}$ and has ranked the lowest. In the case of WS and CG, it has more than $4,000 \mathrm{kcal} / \mathrm{kg}$. This concludes that these materials were suitable as a reinforcing agent for using fuel added to Sewage sludge.

And then it was founded these materials was made up of Carbon and Oxygen from Table III.

\section{B. Conditions}

The results using the program "Minitab" on the extraction condition are shown in Table IV.

Three samples (SS, WS, CG) mostly have carbon and oxygen.

The Calorific Value, which was configured as a dependent variable, were derived from $4,019.96 \mathrm{kcal} / \mathrm{kg}$ to 
$4,396.13 \mathrm{kcal} / \mathrm{kg}$. The three components conducted a three-dimensional analysis and contour plot.
By performing the binary analysis showed the optimal mixed ratio between the two components in Fig. 1.

TABLE II: EXPERIMENTAL DATA ON CHARACTERISTICS OF MATERIALS

\begin{tabular}{|c|c|c|c|c|c|}
\hline \multirow[b]{2}{*}{$\begin{array}{l}\text { Exp. } \\
\text { No. }\end{array}$} & \multirow[b]{2}{*}{$\begin{array}{c}\text { Mixed } \\
\text { Ratio }\end{array}$} & \multicolumn{3}{|c|}{ Independent Variables } & \multirow{2}{*}{$\begin{array}{c}\text { Dependent Variables } \\
\text { Calorific Value } \\
(\mathrm{kcal} / \mathrm{kg})\end{array}$} \\
\hline & & $\begin{array}{l}\text { Sewage } \\
\text { Sludge } \\
(\mathrm{g})\end{array}$ & $\begin{array}{c}\text { Waste } \\
\text { Sawdust } \\
(\mathrm{g})\end{array}$ & $\begin{array}{c}\text { Coffee } \\
\text { Grounds } \\
(\mathrm{g})\end{array}$ & \\
\hline 1 & $2: 1: 1$ & $8.0(1)$ & $4.0(1)$ & $4.0(1)$ & $4,185.71$ \\
\hline 2 & $4: 2: 1$ & $8.0(1)$ & $4.0(1)$ & $2.0(-1)$ & $4,067.32$ \\
\hline 3 & $4: 1: 2$ & $8.0(1)$ & $2.0(-1)$ & $4.0(1)$ & $4,183.86$ \\
\hline 4 & $4: 1: 1$ & $8.0(1)$ & $2.0(-1)$ & $2.0(-1)$ & $4,045.43$ \\
\hline 5 & $1: 1: 1$ & $4.0(-1)$ & $4.0(1)$ & $4.0(1)$ & $4,325.99$ \\
\hline 6 & $2: 2: 1$ & $4.0(-1)$ & $4.0(1)$ & $2.0(-1)$ & $4,188.30$ \\
\hline 7 & $2: 1: 2$ & $4.0(-1)$ & $2.0(-1)$ & $4.0(1)$ & $4,351.46$ \\
\hline 8 & $2: 1: 1$ & $4.0(-1)$ & $2.0(-1)$ & $2.0(-1)$ & $4,185.71$ \\
\hline 9 & $2: 1: 1$ & $6.0(0)$ & $3.0(0)$ & $3.0(0)$ & $4,185.71$ \\
\hline 10 & $2: 1: 1$ & $6.0(0)$ & $3.0(0)$ & $3.0(0)$ & $4,185.71$ \\
\hline 11 & $2: 3: 3$ & $2.0(-2)$ & $3.0(0)$ & $3.0(0)$ & $4,396.13$ \\
\hline 12 & $10: 3: 3$ & $10.0(2)$ & $3.0(0)$ & $3.0(0)$ & $4,080.50$ \\
\hline 13 & $6: 1: 3$ & $6.0(0)$ & $1.0(-2)$ & $3.0(0)$ & $4,183.12$ \\
\hline 14 & $6: 5: 3$ & $6.0(0)$ & $5.0(2)$ & $3.0(0)$ & $4,187.56$ \\
\hline 15 & $6: 3: 1$ & $6.0(0)$ & $3.0(0)$ & $1.0(-2)$ & $4,019.96$ \\
\hline 16 & $6: 3: 5$ & $6.0(0)$ & $3.0(0)$ & $5.0(2)$ & $4,304.10$ \\
\hline
\end{tabular}

TABLE III: THE CONTENT ANALYSIS OF THE PROPERTIES OF WASTE BIOMASS

\begin{tabular}{|c|c|c|c|c|c|c|c|}
\hline \multirow[b]{2}{*}{ Material } & \multicolumn{4}{|c|}{ Proximate Analysis } & \multirow{2}{*}{$\begin{array}{c}\text { Calorific } \\
\text { Value } \\
(\mathrm{kcal} / \mathrm{kg})\end{array}$} & \multirow{2}{*}{$\begin{array}{c}\mathrm{AT} 4 \\
\left(\mathrm{mg} \mathrm{O}_{2} / \mathrm{g}\right. \\
\mathrm{DM})\end{array}$} & \multirow[b]{2}{*}{$\begin{array}{c}\text { Biomass Contents } \\
(\%)\end{array}$} \\
\hline & $\begin{array}{c}\text { Moisture } \\
(\%)\end{array}$ & $\begin{array}{l}\text { Ash } \\
(\%)\end{array}$ & $\begin{array}{c}\text { Volatic matter } \\
(\%)\end{array}$ & $\begin{array}{c}\text { Fixed Carbon } \\
(\%)\end{array}$ & & & \\
\hline $\begin{array}{c}\text { Waste Sawdust } \\
\qquad(\mathrm{n}=4)\end{array}$ & $6.30 \pm 3.51$ & $12.12 \pm 7.81$ & $62.82 \pm 7.87$ & $18.77 \pm 3.42$ & $4,198.64 \pm 285.03$ & $\begin{aligned} & 2.48 \\
\pm & 1.51\end{aligned}$ & 99.63 \\
\hline $\begin{array}{l}\text { Coffee Grounds } \\
\qquad(\mathrm{n}=1)\end{array}$ & 63.01 & 0.55 & 27.54 & 8.90 & $5,014.44$ & 1.5 & 97.13 \\
\hline
\end{tabular}

TABLE IV: ULTERMATE ANALYSIS OF THE SAMPLES

\begin{tabular}{|c|c|c|c|c|c|}
\hline & $\mathrm{C}$ & $\mathrm{H}$ & $\mathrm{O}$ & $\mathrm{N}$ & $\mathrm{S}$ \\
\hline Sewage Sludge & 35.69 & 5.57 & 52.90 & 5.58 & \\
\hline Waste Sawdust & 38.63 & 4.90 & 51.98 & 4.14 & 1.28 \\
\hline Coffee Grounds & 49.32 & 6.74 & 41.71 & 2.23 & N/D \\
\hline
\end{tabular}

Fig. 1, totally shows the relationship among the independent variables. Different levels and sorts of the factor affect the response differently. As amount of WS increase, calories increase. And SS was seen similar aspect. However, it has a weak influence on the variables. As one can see, that'd be found Coffee Grounds have superior on calorific value.

The relationship $\left(\mathrm{SS}-\mathrm{CG} ; \mathrm{X}_{1} \times \mathrm{X}_{3}\right)$ is reported a high value when they has approximately $2: 5$ mixed ratio illustrated in Fig. 2. Also, (WS-CG; $\mathrm{X}_{2} \times \mathrm{X}_{3}$ ) is confirm that has $1: 5$ mixed ratio. It can be concluded that the coffee grounds effect the high calories than the SS or WS.

The relationship ( $\mathrm{SS}-\mathrm{WS} ; \mathrm{X}_{1} \times \mathrm{X}_{2}$ ) is mostly presumed to be influenced by the amount of the SS. The mixed ratio was result in 2: 1. Therefore, it turns out the Coffee Grounds is rather than Waste Sawdust further impact on Sewage Sludge

\section{Optimization Using Response Surface Method (RSM)}

This is a second polynomial regression on raw material conditions of the Bio-SRF demonstrated in Table IV.

The coefficient of determination $\left(\mathrm{R}^{2}\right)$ indicates the explanation of the experiments.

When the independent variables are two or more, it utilizes the adjusted regression value $\left(R^{2}\right.$ adj) and $R^{2}$ should be close to 1.0 for a good statistical model [5]. When the $\mathrm{R}^{2}$ is near to 1.0 , it approximates to the actual value.

TABLE V: POLYNOMIAL EQUATION CALCULATED By RSM PROGRAM

\begin{tabular}{|c|c|c|}
\hline Response & Second order Polynomial equations & $\mathrm{R}^{2}(\mathrm{adj})$ \\
\hline Calorific & $\mathrm{Y}=4206.9-76.96 \mathrm{X}_{1}+1.7 \mathrm{X}_{2}+141.6 \mathrm{X}_{3}$ & \\
Value & $+3.288 \mathrm{X}_{1}^{2}-0.09 \mathrm{X}_{2}^{2}-5.92 \mathrm{X}_{3}^{2}+$ & 0.9872 \\
& $2.91 \mathrm{X}_{1} * \mathrm{X}_{2}-2.91 \mathrm{X}_{1} * \mathrm{X}_{3}-6.01 \mathrm{X}_{2} * \mathrm{X}_{3}$ & \\
\hline
\end{tabular}

$* \mathrm{X}_{1}=$ Sewage Sludge, $\mathrm{X}_{2}=$ Waste Biomass, $\mathrm{X}_{3}=$ Coffee Grounds

This study reports that the coefficient of determination is shown 0.9872 . Thus, it can be suitable for making a product to the modeling results.

The estimated optimal mixing conditions for the production of high - calorie fuel, can be seen from Table V. When the independent variables $\mathrm{X}_{1}, \mathrm{X}_{2}, \mathrm{X}_{3}$ are $2.0 \mathrm{~g}, 1.0 \mathrm{~g}$, $5.0 \mathrm{~g}$, respectively, the maximum value of the calorific value of the dependent variable was predicted $4,574.26 \mathrm{kcal} / \mathrm{kg}$ in 
presented Table VI.

The p-value for Regression model and each variable is identified as less than 0.05

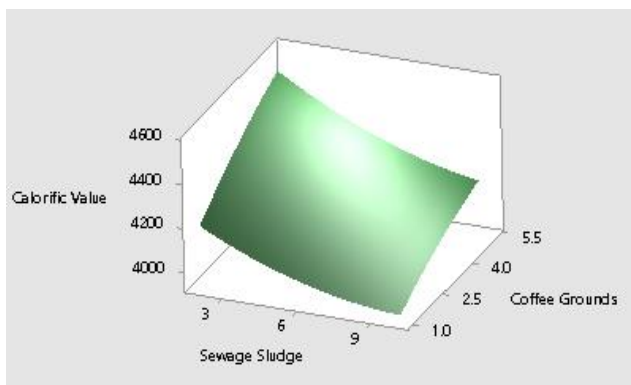

Sewage sludge $\left(\mathrm{X}_{1}\right) \times$ coffee grounds $\left(\mathrm{X}_{3}\right)$

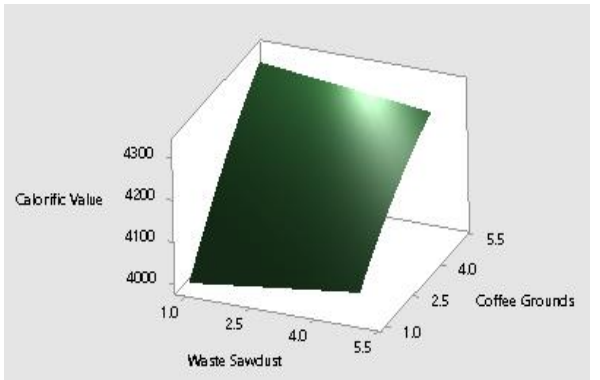

Waste sawdust $\left(\mathrm{X}_{2}\right) \times$ coffee grounds $\left(\mathrm{X}_{3}\right)$
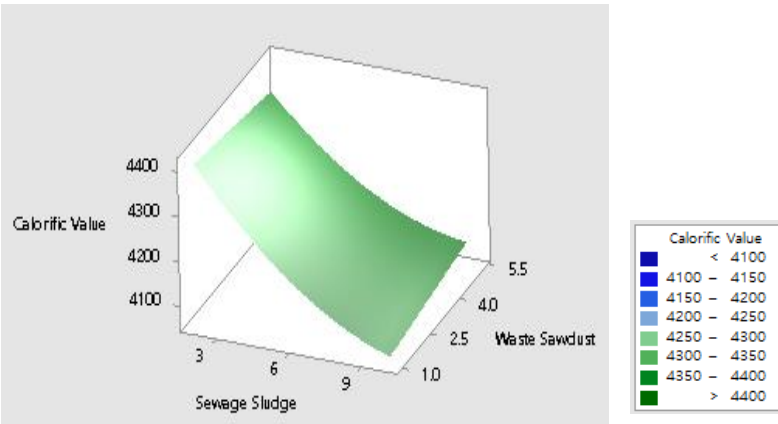

Sewage sludge $\left(\mathrm{X}_{1}\right) \times$ waste sawdust $\left(\mathrm{X}_{2}\right)$

Fig. 1. The three dimensional between two components.

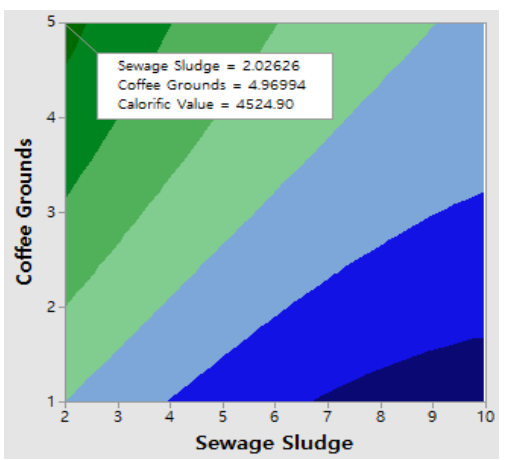

Sewage sludge $\left(\mathrm{X}_{1}\right) \times$ coffee grounds $\left(\mathrm{X}_{3}\right)$

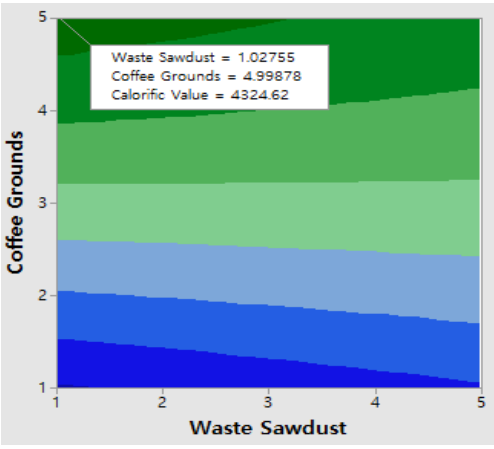

Waste sawdust $\left(\mathrm{X}_{2}\right) \times$ coffee grounds $\left(\mathrm{X}_{3}\right)$

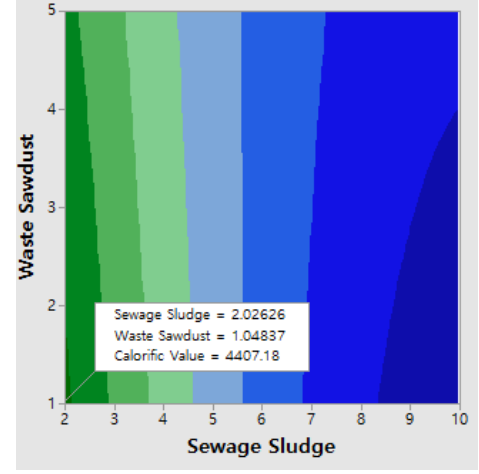

Sewage sludge $\left(\mathrm{X}_{1}\right) \times$ waste sawdust $\left(\mathrm{X}_{2}\right)$

Fig. 2. The contour plot between two components.

TABLE VI: PREDICTED OPTIMUM CONDITIONS FOR THE BIO-SRF

\begin{tabular}{|c|c|c|c|c|c|}
\hline \multirow[b]{2}{*}{ Response } & \multicolumn{3}{|c|}{ Preparation Conditions } & \multirow[b]{2}{*}{$\begin{array}{c}\text { Predicted } \\
\text { Estimate }\end{array}$} & \multirow[b]{2}{*}{$\begin{array}{c}\text { Morpholog } \\
\mathrm{y}\end{array}$} \\
\hline & $\begin{array}{c}\text { Sewage } \\
\text { Sludge } \\
\left(\mathrm{X}_{1}\right)\end{array}$ & $\begin{array}{c}\text { Waste } \\
\text { Sawdust } \\
\left(\mathrm{X}_{2}\right)\end{array}$ & $\begin{array}{c}\text { Coffee } \\
\text { Grounds } \\
\left(\mathrm{X}_{3}\right)\end{array}$ & & \\
\hline $\begin{array}{c}\text { Calorific } \\
\text { Value } \\
\text { (kcal/kg) }\end{array}$ & 2.0 & 1.0 & 5.0 & $4,574.26$ & Maximum \\
\hline
\end{tabular}

The actual experiment makes the progress above the optimal condition. The figure of the calorific value result in $4,627.39 \mathrm{kcal} / \mathrm{kg}$. When producing the waste biomass Bio-SRF in accordance with the above conditions, it would be more than $3,000 \mathrm{kcal} / \mathrm{kg}$ which exceeds the quality standard of the fuel.

\section{Discussion}

Response Surface Methodology used in this study is a statistical analysis to derive the optimum condition with minimal experimentation. Jo et al applied to find the input conditions which become jelly and determine the optimal organoleptic acceptability by measuring acidity and sugar content in "Manufacture of Blueberry Jam" [5]. Also, Seo et al studied to predict the melon cultivation using 3 factors which influence the chemical resistance of the soil (nitrogen, phosphate, potassium) for the concentration of the melon fertigation solution [6]. Thus we have reviewed the applicability as a methodology that predicts the correlation between the composition and the quality standards.

Because there is no mixing standards of sewage sludge in manufacturing of Bio-SRF, it should include more than $40 \%$ under No. GR M 9018-2014 (the Ministry of Knowledge Economy Korean Agency for Technology and Standards Notice) [11]. This study results in 2(Sewage Sludge) : 1(Waste Sawdust) : 5(Coffee Grounds) as the ratio of the max calorific value in case of producing bio solid fuel. It is violated in domestic law as $25 \%$ of sewage sludge mixing ratio, However this is significant in that given the applicable methodology for biomass solid fuel designs. Produced setting ratio of SS more than 4 for legality, the result of optimal simulation show the max calorie $4,436.48 \mathrm{kcal} / \mathrm{kg}$ as 4(Sewage Sludge) : 1(Waste Sawdust) : 5(Coffee Grounds). Therefore, this statistical approach is valuable as a tool to predict various physical properties of the formulation of the product. Raw material product can review the development potential of the fuel wastes and biomass in advance.

There may be a limit to predict the quality of the reaction of the raw material in a fixed coverage as this study is 
assumed that there is no interaction with each other between the raw material mixture. Nevertheless, it is expected to be very useful for the development and design of high quality bio-solid fuel as the RSM used for the empirical figures. As proposed in this study, future research could design the fuel in accordance with the mixing conditions of the various biomass materials considering the limited content in domestic law.

Finally, it requires the mixing of raw materials based on the results of the basic physical properties of various biomass biological and physical-chemical reactions considered to complement and further research methodology.

\section{CONCLUSION}

It is most important to develop low cost-high calory Bio-SRF in domestic. To work toward a goal, It should be studied to using a waste biomass as a fuel. So, it is required to shorten the time and cost of the combinations of components.

In this paper, we studied to verify optimum fuel composition with a minimum of experiments on biomass and conducted Statistics Simulation using Response Surface Methodology.

The results were as follows:

1) The property of the three single components are respectively spread that the moisture content is 79 86\%, $2 \sim 10 \%, 63 \%$ and calorific value is $3,300 \sim 4,300 \mathrm{kcal} / \mathrm{kg}$, $3,500 \sim 4,400 \mathrm{kcal} / \mathrm{kg}, 5,014 \mathrm{kcal} / \mathrm{kg}$.

2) It made independent variables [sewage sludge (2 10g), waste sawdust and coffee gounds $(1 \sim 5 \mathrm{~g})]$ through a preliminary experiment by the Central Composite Design of the Response Surface Method

3) After a production corresponding to the optimal condition, there was a $1.16 \%$ difference in the calorific value of $4,627.39 \mathrm{kcal} / \mathrm{kg}$ more than predicted in $4,574.26 \mathrm{kcal} / \mathrm{kg}$. It was seem to be a cause of the error that used non-homogeneous sample. In order to reduce the error is thought to require screening before the fuel produced.

4) Through the Response Optimer, we easily obtained a high value $4,574.26 \mathrm{kcal} / \mathrm{kg}$ than the $4,396.13 \mathrm{kcal} / \mathrm{kg}$ the maximum of the dependent variable .Thus, it is appropriate to be a methodology for the composition of the high-calorie fuel.

5) The lower the calorific value, the higher the Sewage Sludge. Also, waste sawdust proved insignificant impact by coffee.

In order to use sewage sludge as fuel based on this study, the research needs to be continued to find biomass on positive correlation.

More studies are required a research of diverse biomass' characteristic and keep going methodological complement for physical, biological and chemical reaction of biomass
Whether the problems (exp. Toxic chemicals) exists or not on current law, it should be considered in the research phase.

\section{ACKNOWLEDGEMENTS}

This work (Grants No. C0395625) was supported by Business for Cooperative R\&D between Industry, Academy, and Research Institute funded Korea Small and Medium Business Administration in 2016.

\section{REFERENCES}

[1] D. H. Choi, "Andong University study on bio-drying process for the production of mixed bio-SRF of sewage sludge with coffee grounds," 2014

[2] B. J. Choi, "Development of using sewdust and coal from wood by-products," vol. 1998, no. 6, pp. 419-438, 1999.

[3] Konkuk University Industrial Cooperation Corp, "Manufacturing highly dense pellet or block using waste including coffee waste," 1020130095864.

[4] J. S. Park, O. H. Kim, Y. T. Kim, and W. H. Yeo, "Stochastic Simulation Approach for Bio Solid Fuel Quality Estimation," Journal of Korea Society of Waste Management, vol. 32, no. 8, pp. 827-833, 2015

[5] H. J. Lee, J. R. Do, J. H. Kwon, and H. K. Kim, "Optimization of extration conditions for extracts from cucurbita moschata duch. by response surface methodology," Journal of the Korean Society of Food Science and Nutrition, vol. 39, no. 3, pp. 449-454, 2010.

[6] W. J. Cho, B. S. Song, J. Y. Lee, J. K. Kim, J. H. Kim, Y. H. Yoon, J. I. Choi, and J. W. Lee, "Composition analysis of various blueberries produced in Korea and manufacture of blueberry jam by response surface methodology," Journal of the Korean Society of Food Science and Nutrition, vol. 39, no. 2, pp. 319-323, 2010/

[7] Official Wastes Test Method.

[8] Enforcement Rule on the Promotion of Saving and Recycling of Resources.

[9] Y. Gao, J. Xu, X. Luo, J. Zhu, and L. Nie, "Experiment research on mix design and early mechanical performance of alkali-activated slag using response surface methodology (RSM)," Ceramics International, vol. 42, issue 10, pp. 11666-11673, 2016.

[10] B. Kakavandi, M. Jahangiti-Rad, M. Rafiee, A. R. Esfahani, and A. A. Babaei, "Development of response surface methodology for optimization of phenol and p-chlorophenol adsorption on magnetic recoverable carbon," Microporous and Mesoporous Materials, vol. 231, pp. 192-206, September 2016.

[11] Green Recycled Product Mark, Korean Agency for Technology and Standards, 2015.

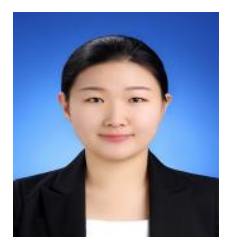

Jin Kyung Jo was born in 1992, Korea. She used to specialize in environmental engineering. Currently, she has been doing her master's degree at development of environmental energy engineering in Incheon National University from 2015.

She is studying hard on bio-fuel under directing of her's professor, Woon Ho Yeo. She has published "a study on the optimization of heavy metals BIO-SRF" at Korea Society of Waste Management in 2015. And then 2015, she has given a presentation about "waste to energy: Bio solid fuel energy source development in Korea" in energy symposium (Asian Institute for Environmental Research and Energy).

She was interested in the attempts to combine the quality of the fuel. She has an experience of a lot of experiments, such as physical and chemical components of waste biomass. To make the efforts, he has learned about Toxic Management. So, Ms. Jo has plans for feasibility of SRF and Bio-SRF studies using biomass. 